\title{
Candidiasis sistémica neonatal
}

\author{
Dra. Gabriela Kunstmann Z. 1; Dr. Gustavo Rencotet $S^{2}$
}

Neonatal systemic candidiasis

\begin{abstract}
A maie preterin newborn infant with systemic candidiasis of hepatic and cardiac localization, is described. The diagnosis was confirmed by positive blood cultures, the presence of Candida albicans in hepatic needle biopsy and microscopical examination of an endocardial right atrial mass. The patient was treated with amphotericin $B$ intravenously together with oral 5-fluorcytosine $(5-\mathrm{l} C$ C) for 80 days, and surgical remoyal of the right atrial mass. After 8 months follow:up his growth and development were normal and there was no evidence of recurtent candida infection.
\end{abstract}

(Key words: Candida albicans, neonatal, septicemia, endo hepatic absces, systemic fungal infection).

La Candida albicans (CA), que forma parte de la flura normal del hombre, invade el torrente circulatorio en circunstancias en que existe un quiebre en las barreras defensivas naturales (indemnidad de picl y mucosas), frente a una alteración de las defensas específicas del huesped, o cuando se produce un desequilibrio del control ejercido por el resto de la flora bacteriana como en el uso de antibióticos ${ }^{1}$.

En el último tiempo se ha observado marcado incremento de la candidiasis sistémica como causa de septicemia neonatal ${ }^{2}$. Su letalidad es elevada, en parte porque el diagnóstico clinico es difícil por ser indistinguible de la septicemia bacteriana $^{3} \mathrm{y}$, además, porque la confirmación del diagnóstico por métodos de laboratorio puede demorar varios dias. Esto hace que el tratamiento oportuno se realice sólo en un $15 \%$ a $40 \%$ de los pacientes con candiđjasis sistémica ${ }^{4}$.

1. Unidad neonatología, Servicio de Pediatría, Hospital San Juan de Dios. S.S.M. Occidente. Departamento de Pediatría, Div. Ciencias Médicas Occidente, Facultad de Medicina, Universidad de Chile.

2. Servicio de Pediatuía, Hospital San Juan de Dios. S.S.M. Occidente, Unidad de cardiología, Departamento de Pediatría, Div. Ciencias Médicas Oceidente, Fiaculrad de Medicina, Úniversidad de Chile.
Los recién nacidos con riesgo mayor son los niños prematuros, aquellos en que se emplean ventilación mecánica ${ }^{3}$, catéteres jntravenosos o intrarteriales, repetidos tratamientos con antibjóticos, alimentación parenteral ${ }^{4}$ y los niños con antecedentes de enterocolitis necrotizante ${ }^{2}$.

Una ayuda importante para hacer el diagnós. tico oportune es el hallazgo de $\mathrm{CA}$ en orina obtenida por punción vesical suprapúbica ${ }^{3}$, y la detección de antígenos circulantes (Mananos) en el suero del paciente 4 .

Por la tendencia propia de la CA para localizarse en điferentes parénquimas (meninges, hueso y articulaciones, sistema urinario, hígado, corazón, etc.) se puede llegar a identificarla, además de los hemocultivos positivos, cultivando material obtenido de esos órganos por punción o haciendo estudios histopatológicos de los mis$\operatorname{mos}^{10}$ como ocurrio en el pacienté descrito a continuación.

\section{Caso clínico}

Recién nacido pretérmino de 34 semanas de gestación, varón, nacido por cesárea, pesó $2.430 \mathrm{~g}$ al nacer. Presentó trastorno respiratorio que requirió ventilación mecánica por seis dias y tratamiento con penicilina y gentamicina en las dosis habituales por ocho días. 
Su cvolucion posterior lue sinlisfactoria hasta Jos 12 dias de vida en que tuvo sintomas y signos clínicos y radioliggious de enterocolitis necrotizantu, razom pur la cuatl se instalo un catéter on vena yugular derecha $y$ se inició ditnetration parenteral y tratamienlo con cloxacilina y ami. lacina.

A la edad de 23 días empeoró registrándose hepatomegalia dura, seplo sistólico mesocárdico grado $23 / 6$. lenconitosis $y$ destiación a la $\mathrm{i} \%$ yuierdit de la seric blantea en el hem ggrantit. Fin la coosonografía hóphitica se observaron inlipenes intrahepáticas anormales (figura li. Lat cintigraf ia hepatcesplénica contirnó un áred dis menor fijación del medio radiosctivo, de alrededor de $2 \mathrm{~cm}$. en el kohulo hepitico derecho e indemnj. dad esplénica (fìgura 2).

$\Lambda$ los 37 diss de vida se efectudo bajo control

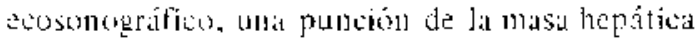
malor. coys estudio dirato y cullive permitiaIon identificar $C$. albicans, la que también fue aisiada desde los hemocultivos.

Fin estas condiciones se inició tratamiento con anfotericina $B(0,50$ ang $x$ kg $x$ día c.v. $)$ más 5 1luoreritocina oral ( $150 \mathrm{mg} \times \mathrm{kg} \times \mathrm{di}$ ia). A pesar de lo que persistio el soplo cardiaco. agregándose edema de las extremidudes inferiores y adenopa lias inguinales. A los 40 dias de vida sufrió an episodio de insuticiemeial citrdiacid, que fue trattatu con diuréticos \& digicálioos. con buena respuesta. La ecocardiogralía realizada a les 44 diás de vida. mostró una masa tumoral en lat auricula derecha (figura 3 ) que fue cortimmidis en el cateterismo cardiaco, que mostró en la cavidad auricular derecha, una masa. con parte mivil, de alrededor de $2 \times 0.8 \mathrm{~cm}$ adherida al tabique y que ocasionalmente provocaba regurgitacion del medio de eontraste hacia la vena eava inferior (figurs 4). Ea un corttrol ecográfico rea. lizado un mes después. a los 45 dias de tratamiento y 82 dias de edad), 10 habian cambios en lid masa auricular por lo que lue operado a los tres meses de edald, en el centro cardiovascular dal Hospital Luis Calvo Mackenda, won circulaLión extracorpórcs, resecundose completanente una masa amarillenta, sésil, ubicada ea el tabique interauricular, que se extendía hatsta cerca de la desembocadura de la vena cava inferjor. La bispsia informó material trombótico que incluye grupos de pseudohifas de C. albicans (figura 5 ).

La evolución posterior fue satisfactoria: mediante ecografías hepaticas seriadas y cintigrafia se comprobó regresión de las masas descritas, la ecografía renal y la ecografía post operatoria fucron normales. La contrainmunoelectroforesis para antígenos de $C$. albicatrs, metabólico y sumático, fue negaiiva. Estudios directos seriados de orina también fueron negativos.

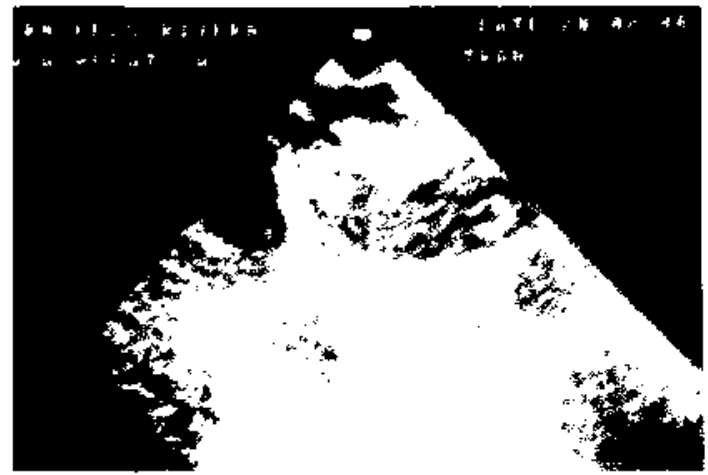

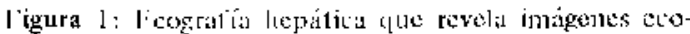

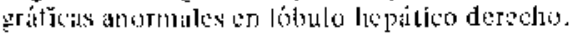
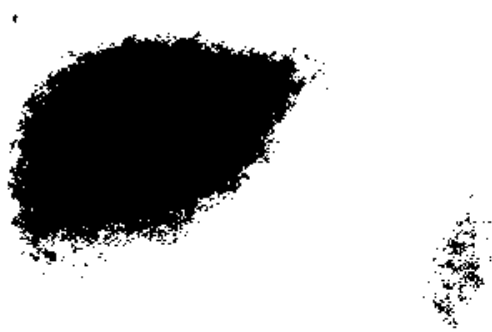

ligura 2: Contigratía liepatoesplénica que muestra imagen de menor fúalición en el lóbulo liepítico derecho r irderandad esplénics.

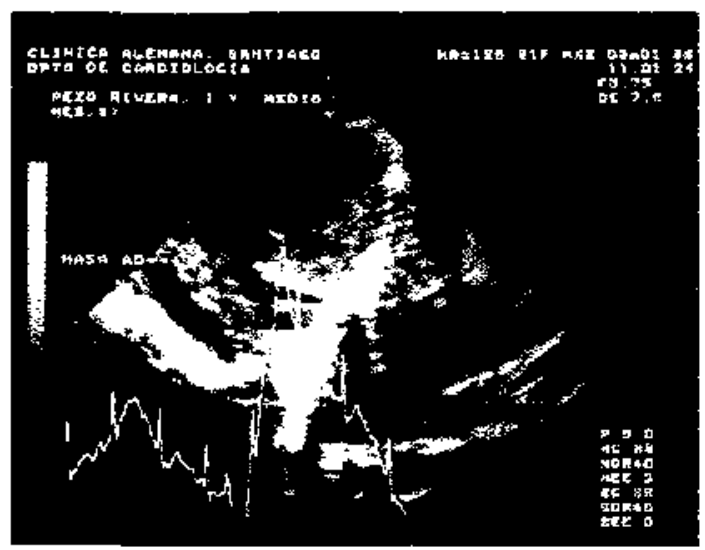

Figuta 3: Itcoeardiografía. Muestra masa tumoral en auricula derecha, de $2 \times 0.8$ cm dependiente del tabjaue interauricular.

Se suspendió anfotericina y fluorocitoninat después de 80 dias de tratamiento, y se dio de alta. En el seguimiento posterior ambulatorio, hasta los ocho meses de edad, el crecimiento pondoestatural y el desarrollo psicomotor han sido normales $y$ no ha habido evidencias de recidivas. 


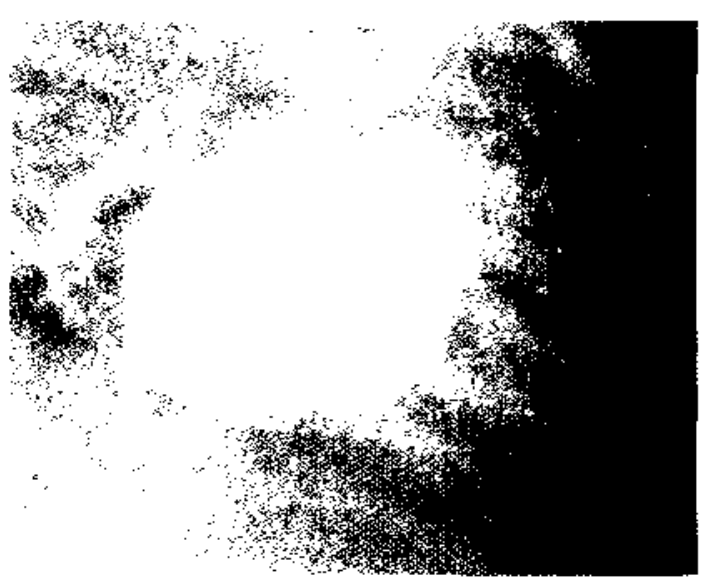

Figura 4: Imagen de la cincangiografía en vision antero. posterior, muestra medis de contraste inycetado por velia cava inferior, tyue rodea la masia intrauricular.

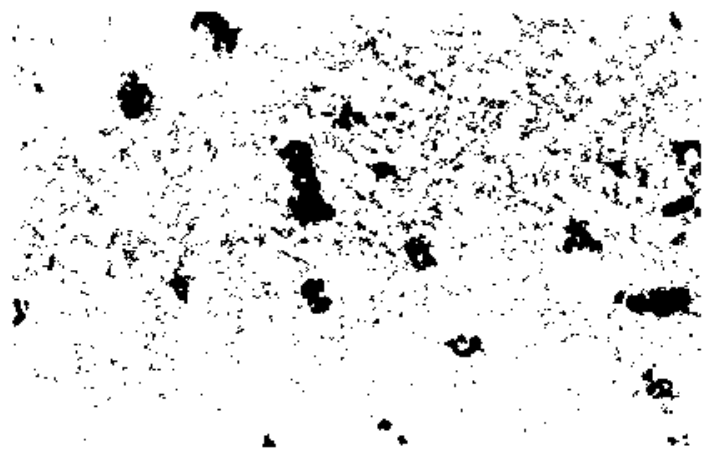

Figura 5: "Micratotogratía de la masa intrabricular derecha extraída "ipuirútelicamente" muestra miaterial trombótico que incluye grupo de pseudohifas de Candida albicans. Cirocent $83 \mathrm{X}$.

\section{COMENTARIO}

La.C. albicans encontrada en este caso correspondio a la forma filamentosa (preudohifas), señalada en la literatura como de mayor posder pátógeno, agresividad, resistencia ${ }^{1}$, y frecuencia en las formas sistétnicas de candidiasis ${ }^{2} 4$. La positividad de los hemocultivos, que permitió confirmar la sospecha clínica. es atortunada: en la literatura se señala que su rendimiento es bajo pues no da resultados en $56 \%$ de los casos de candidiasis diseminada comprobadas por autop$\operatorname{sia}^{4,10}$. El estudio microscópico directo del material extraído por punción hepática resultó útil. cuno en otros casos ${ }^{10}$, pues reveló levaduras e hifas, y permitió establecer una unidad nosológi(ะ).

El tratamiento quirúrgico parece ser mandatorio en el manejo de la endocarditis causada por CA con el fin de evjtar la aparición de fenómenos embólicos ${ }^{12}$ y problemas mecáricoss que pueden derivar en insuficiencia cardíaca, circunstancia observada en nuestro paciente. Otros tipos de tumores cardíacos eran poco probables ${ }^{9}$.

En el paciente descrito no se detectó compromist urinario, a diferencia de otros casos, en que se señalia como hecho frecuente $2,3,11$.

La detección de candidiasis diseminada es, principalmente, un problema clínico, pero su confirmación definitiva sólo se puede tener cuando el estudio histológico demuestra invasión visceral ${ }^{6}$

El tratamiento médico de elección es la anfotericina $B^{6,7}$ : que puede causar diferentes tipos de toxicidad, entre cllas hipotension, fiebre, arrituias o alterationes electroliticas (hipokalemia).

La asociación de anfotericina $\mathrm{B}$ con 5.fluoro. citocind ha sido útil, of rece cierto grado de sinergismo y evitaría la aparición de resistencia a la tluorocitocina $a^{7-11}$. La toxicidad de esta última se caracleriza preferentemente por alleraciones de la función hepática y depresión medular. Durante el tratamiento con ambas drogas se requiere vigilar hematocrito, creatinemia, nitrogeno ureico, kalemia y recuentu de plaquetas ${ }^{8}$. Dichas mediciones, seriadas, no mostraron et este niño alteracioncs, indicando buena toleranLía al tratamiento. No se sabe cuál es la duración óptima de ta terapia y es dificil precisarla mienIras no se cuente con determinacimes seriadas de antigenemia ${ }^{2,4}$, requiriéndose un cuidadoso seguimiento clirico pusterior, para asegurar la ausencial de recidiyas.

\section{RESUMEN}

Lis recièn nacido pretérmino sufrió una candidiasis sistémica con lucalización hepiticia $y$ cardíaca. El diagnóstico fue confirmado por medio de hemocultives e identificación de $C$. albicans en el material extraido por punción hepálica y en el estudio microscópico de una masa cxtirpada de la auricula derecha. El paciente fue tratado con anfotericina $B$ endovenosa, fluorocitocina oral durante 80 dias y extirpacion quirúrgica de la masa auricular, obteniéndose remisiótl total de sus síntumas y signos. E1 seguimiento se ha extendido hasta los 8 meses de edad, su crecimiento y desarrollo han sido normales y no ha babido evidencias de infección.

\section{AGTADECIMIENTOS}

Los autures jegradecen, por la iyuda en el estudio ceocirdiogrático, al Departamento de Cardiología de la Clínica Alemana $y$ al Dr. Otto Philippi R.: y al Dr. Oscar Gomez V. del Centro (ardiovascular del Hospital Luis Calvo Mukenma. por lis resolucion quirúrgica del caso. 


\section{REFERENCIAS}

1. Garcia, Rodrigtez, I.A.: Hongos Oportunistus. en Pumarola, $A$ ed. Micsobjología y Parasitología Médica. Barcelona Salvat Ed. S.A. pág. 733. 1984.

2. Schreiber, J.R., Maynard, E., Lew, M.A.: Candidit Antigen Dectection in Two Premature Veonates witl Disseminated Candidiasis. Pediatrics 74: 838. 1984.

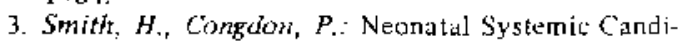
diasis. Arch Dis Child 60* 365, 1985.

4. De Repentigny, L., Reiss, $E_{4}$ : Current Trends in Immunodiagnosis of Candidiasis and Aspergilloxis. Rev Infect Dis 6: 301, 1984.

5. Dee, T.H., Rytel, M.W.: Detection of Serum Precipitins by Counterinmunolectrophotesis: an Adjunet in Deterníning signiticant Candidiasis. J Clin Mictobiol 5: 453, 1977.
6. Edwards, J.E. Severe Candidal Infections. Ann Intern Med 89: 91, 1978.

7. Koldin, M.I. Medoff, $G$.: Antifungal Clienotherapy. Pediatr Clin North Am 30: 49, 1983.

8. Medoff, G., Nohalashi, G.S.: Strategies in the Treatement of Systemic l'ungal Infections. V Fingl J Med 302: 145, 1980.

9. Edwards, JE.: Cardiat 'lumots, in: Forrest II.A., Fimmenuailides G.C. ed. J. Moss'Heat Disease in Infints. Childrew and Adolescents 3rd. lidition Baltimore London Willianss Wilkins. píg. 741, 1983.

10. Tashijon, I., Abramon, J., Peacock, J.: Tocal Heparic Candidiasis. Rev Infect Dis 6: 689, 1984.

11. Pappu, L.D. Purohit, D.M., Bradford, B.F.: Prinary Renal Camdidiasis in Two Preteron Neonates. Am J Dis Child 138: 923, 1984.

12. Cteary, T.G., Koht, S.: Anti Infective Therapy of Infectious lindocarditis. Pediati Clin North Am 30: 349. 1983. 